\title{
ONE-DIMENSIONAL ATTRACTOR FOR A NON-AUTONOMOUS STRONGLY DAMPED LATTICE SYSTEM WITH PERIODIC DRIVING FORCE
}

\author{
HONGYAN LI
}

Abstract. In this paper, we consider one-dimensional attractor of a non-autonomous second order strongly damped lattice system with periodic driving force under Neumann boundary condition or periodic boundary condition. We obtain the existence of a global attractor and prove this attractor is homeomorphic to the circle.

Mathematics subject classification (2010): 35B40, 35B41.

Keywords and phrases: global attractor, strongly damped lattice system, homeomorphism.

\section{REFERENCES}

[1] T. Caraballo, A.N. Carvalho, J.A. LAnga, F. Rivero, A non-autonomous strongly damped wave equation: Existence and continuity of the pullback attractor, Nonlinear Analysis: Theory, Methods and Applications, 74, 6 (2011), 2272-2283.

[2] V.V. Chepyzhov and M.I. Vishik, Attractor of Equations of Mathematical Physics, Amer. Math. Soc., Province, RI, 2002.

[3] I. Chueshov AND I. LASIECKA, Long-time Dynamics of a Semilinear Wave Equation with Nonlinear Interior/Boundary Damping and Sources of Critical Exponents, Contemporary Mathematics, AMS, Providence, RI, 2007.

[4] F. DelL' Oro, V. PATA, Long-term analysis of strongly damped nonlinear wave equations, Nonlinearity, 24, 12 (2011), 3413-3435.

[5] R. IKEHATA, Asymptotic profiles for wave equations with strong damping, Journal of Differential Equations, 257, 6 (2014), 2159-2177.

[6] P. KокCKI, Conley index of invariant sets for strongly damped hyperbolic equations at resonance, arXiv:1404.3429v1.

[7] M. Levi, F.C. Hoppensyeadt, W. L. Mirnker, Dynamics of the Josephson junction, Quart. Appl. Math., 7, 1 (1978), 167-198.

[8] H. Li, S. ZHOU, Structure of the global attractor for a second order strongly damped lattice system, Journal of Mathematical Analysis and Applications, 330, 2 (2007), 1426-1446.

[9] G. LIN, F. XIA, G. XU, The global and pullback attractors for a strongly damped wave equation with delays, International Journal of Modern Nonlinear Theory and Application, 2 (2013), 209-218.

[10] R. MARTINS, One-dimensional attractor for a dissipative system with a cylindrical phase space, Discrete and Continuous Dynamical Systems, 14, 3(2006), 533-547.

[11] V. PATA AND S. ZELIK, A remark on the damped wave equation, Communications on Pure and Applied Analysis, 5, 3 (2006), 611-616.

[12] M. QIAn, W. QIN AND S. ZHU, One-Dimensional global attractor for discretization of the damped driven sine-Gordon equation, Nonlinear Analysis: Theory, Methods and Applications, 34, 7 (1998), 941-951.

[13] C. SUn, D. CAO, J. DUAN, Uniform attractors for nonautonomous wave equations with nonlinear damping, SIAM Journal on Applied Dynamical Systems, 6, 2 (2007), 293-318.

[14] R. Té MAM, Infinite-Dimensional Dynamical Systems in Mechanics and Physics, Appl. Math. Sci. 68, Springer-Verlag, New York, 1988. 
[15] G. WANG, S. ZHU, Dimension of the global attractor for the discretized damped sine-Gordon equation, Applied Mathematics and Computation, 117, 2-3 (2001), 257-265.

[16] R. XU, Y. YANG, Y. LIU, Global well-posedness for strongly damped viscoelastic wave equation, Applicable Analysis: An International Journal, 92, 1 (2013), 138-157.

[17] K. ZENNIR, Growth of solutions with $L^{2(\rho+2)}$-norm to system of damped wave equations with strong sourses, Electronic Journal of Mathematical Analysis and Applications, 2, 2 (2014), 46-55.

[18] S. ZHOU, Global attractor for strongly damped nonlinear wave equations, Functional Differential Equations, 6 (1999), 451-470. 